\title{
LA IMAGEN DE LA MUJER EN LA NÁUTICA DEPORTIVA
}

\author{
Esperanza Molina. Universidad Jaume I (España)
}

\section{Introducción: Un mundo de hombres a la medida de los hombres}

Por más que se afirme que el mundo es de hombres y mujeres por igual, y que hombres y mujeres están capacitados para ejercer las mismas profesiones, hay temáticas que se han atribuido siempre al género masculino, aun cuando la práctica y la realidad ha demostrado que los hombres por sí sólo no lo podían llevar a cabo y necesitaban del complemento de las mujeres, o cuando las mujeres han conseguido resultados que superan a los de los hombres y son capaces de desarrollar la misma labor.

Este trabajo se centra en el tema de la imagen de la mujer en la náutica deportiva: vela y pesca, a través de un estudio comparativo de tres revistas editadas por una misma editorial, en un mismo periodo de tiempo, principios del 2004: Curt Ediciones, en la que estos temas se tratan por separado en las revistas 100 × 100 Regata, dedicada a la vela de competición, y Pesca a Bordo, dedicada a la pesca de competición; y de forma conjunta en Skipper, dedicada a reportajes diversos de pesca y vela.

El objetivo fundamental, al realizar tal elección, era observar cómo se trataba a la mujer y su presencia activa en las páginas de información y la publicidad, en relación con la modalidad deportiva. Poder observar hasta qué punto tenía presencia la mujer en unas u otras publicaciones, y si variaba el enfoque que se daba a la mujer en relación con la modalidad deportiva.

Algunas de las preguntas que se formulaban en el momento de iniciar el estudio fueron:

- ¿Las revistas están dirigidas a hombres o a mujeres?

- ¿Recibe la mujer un tratamiento igualitario al del hombre?

- ¿En qué medida se utiliza la imagen de la mujer como fetiche en la información y la publicidad de las revistas de pesca y vela?.

De forma meramente complementaria, se ha analizado el tratamiento de la mujer en otras revistas náuticas especializadas existentes en el mercado, en las que se da la coincidencia de que las redacciones o la dirección están protagonizadas por un mayor número de mujeres que de hombres: Navegar, Barcos a Vela, Barcos a Motor o Náutic Press.

Atendiendo a la situación de la náutica surgieron, a su vez, otras preguntas derivadas de este segundo análisis como:

- ¿Cómo influye el hecho de que cada vez haya más mujeres navegantes y más mujeres al frente de estas revistas dirigidas fundamentalmente al sector masculino?.

- ¿Qué lenguaje utilizan las mujeres para vender un producto masculino como el de las revistas náuticas y con qué intencionalidad? 


\section{Metodología}

En el análisis de las publicaciones de la editorial Curt Ediciones, el análisis pormenorizado se basó en los siguientes aspectos: un método de análisis cuantitativo en cuanto al volumen de paginación. Espacio dedicado a información. Espacio dedicado a publicidad. Textos y espacio informativo en el que se cita o se dedica a la mujer y el lenguaje empleado. Número de fotografías dedicadas a las mujeres. Aparición de imágenes de la mujer en publicad y su tratamiento.

En cuanto al estudio genérico de las otras revistas, se tuvo en cuenta el staff, composición de las redacciones, dirección de las revistas, tratamiento de los temas de pesca y vela, y mensajes publicitarios.

\section{La pesca: un mundo masculino con una presencia fundamental de la mujer}

Para poder analizar ambas cuestiones es preciso hacer antes una pequeña introducción sobre el origen de la náutica deportiva, asociado a los géneros masculino y femenino.

La náutica, profesional o deportiva, ha sido concebida siempre como un mundo de hombres, en el que sin embargo no han estado ajenas las mujeres.

Comentaba el ingeniero náutico, Manuel Ruiz Elvira, diseñador del barco del equipo Alinghi que ganó la copa América en Nueva Zelanda en el 2003, durante una conferencia en el Instituto Valenciano de Arte Moderno, que el origen de la competición náutica puede enlazarse fácilmente con la historia de los grandes bacaladeros que tenían como reto salir a pescar más lejos que sus competidores, llegar en el menor tiempo a la zona de pesca, poder pescar lo más posible, y retornar a puerto los primeros para poder vender su pescado al mejor precio.

Ese resumen, con el que Manuel Ruiz Elvira aludía al origen de la competición de regatas en su conferencia sobre "El diseño técnico de los veleros", define lo que ha sido la industria pesquera, pero también el nacimiento y evolución de la náutica deportiva, que se ha ligado tradicionalmente a la figura del hombre, al sector masculino.

Eran los hombres los que salían a pescar, los que protagonizaban socialmente este trabajo en el que la presencia de la mujer resultaba imprescindible, y sin embargo, quedaba relegada a un segundo plano.

El hombre salía a la mar, a pescar, pero la mujer era la encargada de llevar todo el peso del hogar y la familia. En la pequeña industria pesquera correspondía a la mujer la obligación de reparar los artes de pesca, de remendar las redes, y en muchos casos era la encargada de pujar para hacerse con el mejor pescado que salía del mar, de venderlo en mercado 
para conseguir el beneficio que sustentaba a toda la familia.

En consecuencia, la pesca era un trabajo que implicaba tanto al hombre como a la mujer, pero se asocia únicamente a la dureza del papel del pescador hombre.

Miguel Senet en su libro "Memorias del Grao de Castellón" (SENET, M; 1993) refiere perfectamente el papel de la mujer grauera de Castellón, que como otras miles de mujeres en los pequeños puertos de pescadores, tenían la misión de esperar la llegada de las barcas de pesca, recoger el pescado que se pesaba y se adquiría en la misma arena de la playa, e ir a venderlo al día siguiente para obtener el mejor precio en el mercado. La mujer también asumía la labor de remendadora y tenía la obligación de coser las redes para que pudieran reutilizarse en cada faena. Sin redes y aparejos, no se podía salir a pescar.

Como indica Raymond Williams: "La cultura incluye la organización de la producción, la estructura de la familia, la estructura de las instituciones que expresan o gobiernan las relaciones sociales y las formas características a través de la que se comunican los miembros de la sociedad" (Williams, R (1958); "Cultura y Sociedad 1780-1950 De Coleridge a Orwell").

El reparto de papeles en la pesca, se integra perfectamente en una visión de la cultura que otorga al hombre un papel activo y a la mujer un papel pasivo. Las diferencias sexuales se identifican con las diferencias culturales y laborales. La mujer, por su posibilidad de ser madre, desde el discurso patriarcal, queda sujeta al hogar y las labores calificadas como "menores", que complementan las labores del hombre, que asume, de esta manera, el dominio social y político de su entorno.

La importancia social del papel de la mujer sigue condicionada al papel predominante del hombre. El sentido de las teorías freudianas del psicoanálisis, a las que se refiere Laura Mulvey (MULVEY, 1975), explican la relación desde la definición de una sociedad basada en el "Falocentrismo: dependencia de la imagen de la mujer castrada para dar orden y sentido a su mundo". Laura Mulvey, en su artículo sobre 'Placer visual y el cine narrativo' hace referencia a la teoría del psicoanálisis de Freud, como ser castrado que tiene que mantenerse en un segundo plano, y pierde relevancia por si mismo, alcanza su importancia a través del otro ser completo, el hombre. "La mujer permanece, entonces, en la cultura patriarcal como significante para el otro del macho, prisionera de un orden simbólico en el que el hombre puede vivir sus fantasías y obsesiones a través de del mandato lingüístico imponiéndolo sobre la imagen silenciosa de la mujer, vinculada permanentemente a su lugar como portadora del sentido, no como constructora del mismo".

\section{La náutica deportiva: la mujer sigue en segundo plano}

La náutica deportiva no es sino una continuidad de un trabajo convertido en deporte y ocio, y de una identificación cultural falocrática que sigue asociada al hombre en sus modalidades de pesca y vela. Es el hombre el que aparece como punto de referencia de la competitividad. La fuerza del hombre, la 
habilidad del hombre, la dureza del hombre... pero la mujer también está ahí presente, ocupa un papel activo en muchas modalidades, pero aparece siempre en un segundo plano, como objeto pasivo. La imagen de la mujer, su papel activo y social sigue relegada y sujeta a la imagen masculina. Los modelos son masculinos.

Rosa Ma Rodríguez Magda en “¿Feminización de la cultura?” Hace referencia al espejo y la mirada y pone en entredicho si la mujer construye su propia identidad por si sola o como un reflejo de la identidad masculina culturalmente aceptada. En el sector de la náutica, el modelo a seguir es masculino. "La mujer cuando se mira se reconoce como objeto, y en este sentido, femeninamente, pero cuando ejerce esta mirada no lo hace como sujeto autónomo, sino a través de la mirada masculina. Es el sujeto masculino el que la mira cuando ella pretende adoptar la posición de sujeto. Para construir su género, cambia alternativamente de género, lo cual es realmente paradójico." (RODRÍGUEZ MAGDA, Rosa Mª; 2002)

La mujer debe mirarse en la mirada del hombre, en la conceptualización de la náutica impuesta por el hombre, para luego buscar su propio papel dentro de esta modalidad.

Socialmente, ambos deportes, la vela y la pesca, se consideran deportes masculinos. Pese a que la mujer cada vez tiene un mayor peso específico en estos sectores, su papel sigue siendo secundario. Por otra parte, dependiendo de la modalidad náutica, la presencia de la mujer también resulta muy desigual. En vela, la mujer cada vez más tiende a igualarse con el hombre, al menos en el plano teórico. En la pesca y el motor, el hombre domina la actualidad, tanto en la teoría como en la práctica.

a) Vela Ligera: En las modalidades deportivas de vela ligera, tanto las mujeres como los hombres ocupan un papel de iguales. No se cuestiona su participación ni su sexo.

b) Vela de cruceros: En la modalidad de la vela de cruceros, prima la presencia del hombre. La presencia de la mujer es cada vez más importante, pero la mayor parte de las tripulaciones son masculinas. La igualdad es ficticia.

Un ejemplo que ilustra dramáticamente esta situación de desigualdad, ha quedado reflejado tras la celebración de los juegos Olímpicos de Atenas 2004. España consiguió una medalla de oro y dos de plata en vela ligera en las modalidades olímpicas de '49er', 'tornado' y '470'. Una de estas medallas fue ganada con todos los honores por la pareja femenina integrada por Natalia Via-Dufresne y Sandra Azón. Los medallistas olímpicos masculinos, Iker Martínez y Xavier Fernández en '49er' y Rafa Trujillo, en 'Tornado', recibieron inmediatamente diferentes ofertas para navegar como profesionales en los equipos de élite españoles y los equipos internacionales participantes que tienen intención de competir en la Copa América Valencia 2007. Las medallistas femeninas, Natalia Via-Dufresne y Sandra Azón, tras la celebración de su éxito, eran 'excluidas' de este festival de oportunidades. 
Redactoras especializadas en el sector de la náutica explicaban con recelo esta cuestión: "Son muy buenas. No tienen la fuerza necesaria para asumir algunos de los puestos de un crucero de competición, pero como tácticos, pilotos, o estrategas no tienen precio. Lo que pasa es que esos son puestos de poder dentro de un barco y una mujer nunca tiene acceso a ellos".

Una vez más la estructura patriarcal a la que hacen referencia autoras como $M^{a}$ José Gámez, Laura Mulvey, o Tania Modleski, impone sus condiciones. "En nuestra cultura, la tolerancia y la pasividad se consideran características femeninas, y como consecuencia, cualidades apropiadas para las mujeres pero no para los hombres". (MODLESKI, T referenciada por KUHN, Annette (2002) en "Géneros de Mujeres. Teoría sobre el melodrama y el culebrón"). La mujer, igual o no, no es sino un reflejo pasivo. No tiene acceso a los puestos de poder en una sociedad en la que el hombre tiene miedo a perder los puestos de control.

c) Pesca: En la modalidad de pesca deportiva o 'motor', la presencia masculina sigue siendo predominante en todos los aspectos. El hombre absorbe casi todo el protagonismo activo y la mujer es considerada, casi siempre, un objeto de deseo que aumenta el sello de calidad del barco. En este sector, las diferencias son más evidentes, más palpables.

\section{Análisis del contenido publicitario e informativo de las revistas náuticas}

El análisis pormenorizado de las tres revistas de una misma editorial, Curt Ediciones, que diferencian sus contenidos en Vela, Motor y Náutica (mixta) aporta datos muy interesantes al respecto del tratamiento de la mujer.

1.- "100 x 100 Regata” (vela): dedicada a la vela de competición. El análisis cuantitativo de la información demuestra que la presencia de la mujer es minoritaria y apenas ocupa un $5 \%$ en el mejor de los casos, tanto en número de fotografías como en el texto referido a ellas. El tratamiento de la información, sin embargo, cuando aparece la imagen de la mujer, es homogéneo. La mujer está considerada un igual, cuando tiene presencia activa en la competición.

En cuanto a la publicidad insertada en el medio, se constata la ausencia casi total de publirreportajes y el predominio de la inserción de páginas de publicidad en las que predomina la imagen del hombre. La inserción de la mujer en esta publicidad es minoritaria. La imagen de la mujer, cuando aparece, puede estar representada como patrón o tripulante, igual que un hombre. Cabe reconocer, sin embargo, que como la revista está dirigida a hombres, y son estos los que dominan la competición y la compra del producto, la presencia de la mujer, es puramente simbólica.

2.- "Pesca a Bordo" (Pesca-motor): La presencia de la mujer en los textos informativos y fotografías es nula, prácticamente no existe. La revista está dedicada a un público masculino. Se pone de relieve el carácter competitivo, la rudeza del deporte y la habilidad masculina para desarrollarlo. La imagen de la mujer en publicidad es mayoritaria como objeto referencial pasivo: la 
mujer feliz que acompaña al hombre varonil capaz de conducir la mejor embarcación. La mujer como fetiche decorativo que embellece e incrementa la calidad y belleza del barco que se ofrece. Y la mujer como fetiche erótico, que parece estar ligada al producto de venta y trasmite el mensaje más sugerente: 'el hombre que compre el barco estará plenamente satisfecho sexualmente'.

La mujer es un objeto pasivo ante la mirada del hombre que sueña, imagina, y despierta su interés activo por el dominio del medio, el mar, y su propio ego, la masculinidad reflejada en el cuerpo de la mujer.

3.- "Skipper (náutica motor y vela): ambos contenidos, vela y motor, quedan representados a la perfección en la tercera de las publicaciones de la misma editorial, que recoge temas de embarcaciones de recreo a vela o a motor, viajes, temáticas náuticas en general.

La presencia informativa de la mujer es muy pequeña. Esta revista, que dirige su mercado hacia un tipo de navegante genérico, está enfocada de manera predominante hacia los hombres, aunque la mujer también aparece en algunos artículos. El contenido informativo de esta revista es muy pequeño, a pesar de su enorme paginación (más de 200 páginas). La mayor parte de su contenido está integrado por publirreportajes. El grueso de su contenido se refiere a motores, aparejos náuticos, viajes, embarcaciones y temas prácticos relacionados con la navegación.

El contenido publicitario es enorme, y en él se engloban los publirreportajes de barcos, mercado náutico de primera y segunda mano, publicidad dura y pura, charter, y viajes. La utilización de la mujer en la publicidad náutica relacionada con la vela es muy pequeña. En los casos en que se introduce la imagen de la mujer, lo hace como patrona, tripulante, y solo en algunos casos, apenas insignificantes como fetiche erótico. Esta última utilización está relacionada siempre con barcos de vela de gran lujo. Solamente en estos casos, la mujer aparece con poca ropa y en posiciones sugerentes. Pero en términos estadísticos la presencia es inapreciable.

La publicidad náutica, tanto en los 'publirreportajes' en los que impera la línea editorial como en la publicidad elaborada por los anunciantes relacionada con los barcos a motor y a vela es completamente diferente en la misma revista. En vela, la mujer puede ser protagonista; en motor, la mujer pierde completamente cualquier papel de protagonismo activo para adquirir el de complemento familiar del hombre, y convertirse en referente pasivo:

- La mujer que acompaña y admira al varón posicionado firmemente delante del timón.

- La mujer en bikini con poses sugerentes, que acompaña al varón mientras este demuestra su maestría al frente del timón.

- La mujer que embellece la proa o la popa del barco en posición sugerente de 'ven y tómame', mientras el hombre, con pose segur, conduce la embarcación o se sienta al lado de la bella modelo, convenientemente vestido.

- Y la aparición de varias mujeres con pose sugerente en traje minúsculo de baño, repartidas por la embarcación, que admiran a uno 
o varios hombres a los que rodean en una promesa de satisfacción sexual que induce a una relación emocional de 'cama redonda', por lo bien que conducen, pilotan sus embarcaciones, y lo poderosos que son al adquirir ese tipo de barco.

\section{Conclusiones iniciales: La mujer como igual en vela, como objeto pasivo en motor}

La comparación del tratamiento informativo y publicitario de la imagen de la mujer en las tres publicaciones permitiría establecer una serie de conclusiones iniciales:

1. La presencia de la mujer es nula o escasa en las revistas náuticas.

2. Las temáticas de vela consideran a la mujer como "iguales", dentro de su escasa representación,.

3. Publicidad en vela: Poca presencia de la mujer. Escasa utilización de la mujer como representación erótica.

4. Publicidad en Pesca y Motor: La utilización de la mujer como fetiche erótico es prioritaria en las revistas de motor y pesca.

5. Cuanto mayor es el tamaño del barco y su lujo, se multiplica la presencia de las mujeres y el reclamo sexual del anuncio.

\section{Análisis en profundidad: otra visión de la presencia de la mujer en la náutica.}

\section{La presencia de la mujer es nula o escasa en las revistas náuticas.}

Estas conclusiones se relacionan y corresponden con muchos de los comentarios expresados con algunas de las autoras de artículos de género, que conviene tener en cuenta para poder esbozar conclusiones mucho más amplias. Como ya se ha indicado, el sector de la náutica deportiva mantiene la primacía del hombre como destinatario de esa información, y por tanto como modelo y protagonista, presente en las tres publicaciones de esta editorial. Si bien se podría llegar a pensar que el tratamiento de la mujer en la información relacionada con la vela responde a la poca presencia de la mujer en la actualidad deportiva, y que la publicidad tiende a respetar la imagen femenina en atención a su propia identidad, la lectura, atendiendo a las teorías freudianas y a los comentarios expresados por diferentes autoras también pueden presentar una lectura completamente diferente.

Annette Kuhn en "Géneros de Mujeres. Teoría sobre el melodrama y el culebrón" se pregunta: "¿qué significa dirigirse a una audiencia de mujeres? ¿Qué es exactamente lo que lo que se está indicando cuando se habla a una audiencia marcada por el género? ¿Hay que entender a las mujeres como un subgrupo de la audiencia social distinguible a partir de discursos que construyen a priori categorías de género? O ¿referirse a una audiencia de mujeres alude más bien a la relación espectador/-a texto marcada por el 
género, por la diferencia sexual tal y como se construye en las relaciones entre espectadores y textos?" (KUHN, 2002), Se podría pensar entonces... ¿La mujer tiene poca presencia en estas publicaciones porque contribuye en menor medida a esa actualidad náutica, o porque su aportación siempre está prejuzgada por su diferencia sexual?.

El caso de las regatistas olímpicas de 470, Natalia Via-Dufresne y Sandra Azón, podría dar múltiples interpretaciones. A pesar de que su triunfo fue absoluto en Atenas, la hazaña de sus compañeros masculinos dio que hablar durante meses, mientras ellas quedarán relegadas enseguida a un segundo plano.

\section{Las temáticas de vela consideran a la mujer como "iguales", dentro de su escasa representación}

Esta afirmación, evidente en el primer análisis, también está sujeta a otras interpretaciones que nos darían conclusiones muy diferentes. Volviendo a los comentarios realizados por Rosa $\mathrm{M}^{a}$ Rodríguez Magda, en "La feminización de la cultura", cuando expone su hipótesis sobre el espejo o la mirada: "La mujer cuando se mira se reconoce como objeto, y en este sentido femeninamente; pero cuando ejerce esta mirada no lo hace como sujeto autónomo, sino a través de la mirada masculina...". (RODRÍGUEZ MAGDA, Rosa $M^{a}$, 2002) ¿Realmente se realiza un tratamiento de iguales?. En la vela, la mayoría de los anuncios publicitarios recogidos en 100 x 1000 Regata y Skipper, muestran siempre modelos masculinos. Es preciso volver a preguntarse si lo que se pone de relieve es un tratamiento de igualdad o de exclusión. Si la mujer es tenida en cuenta como individuo, o si su misma diferencia sexual no la deja aparte, referenciada en una concepción de modelos masculinos que reduce sus papeles de forma drástica, como reflejo o, incluso, como la mascarada a la que alude Eva Parrondo en Feminidad y Mascarada. (PARRONDO, Eva. 1996)

La mujer que quiere sobresalir tiene que adoptar un modelo creado de antemano y convertirse en algo que no es, enmascararse para poder luchar con las mismas armas que los hombres con los que compite. Por otra parte, aunque los anuncios publicitarios relativos a la vela, muestran en algunas ocasiones a la mujer como "patrón" o tripulante, en mucho casos su presencia se construye más desde el aspecto de la madre de familia que 'acompaña' al líder masculino a bordo de su velero, o como elemento secundario que corrobora el lujo de la oferta realizada. Esto es, existe una diferenciación sexual que afirma a la mujer como 'madre', objeto que protege la identidad del hogar, la seguridad de la familia y, por tanto, garantiza la seguridad del producto que se vende y en el que domina el modelo masculino como protagonista al que va dirigida la publicidad.

$M^{a}$ José Gámez en "Cinematografía. La madre en el cine y la literatura de la democracia española", en el capítulo 2, "antecedentes psicoanalíticos: la figura materna en el desarrollo del sujeto", hace referencia a las distintas teorías que representan a la mujer como un individuo castrado, obligada a 
seguir los dictados de una cultura predominante, marcada por el falo, que siempre la relega a un papel secundario, pasivo y dominado. (GÁMEZ FUENTES, $M^{a}$ José. 2004) El protagonismo de la mujer siempre es cuestionado, y solo es permitido como un elemento secundario. Puede ser la patrona de su barco, pero solo de forma excepcional, y desde esta excepcionalidad vuelve a remarcar el papel falocentrista que rige el sector de la náutica y la elaboración de artículos o publicidades en estas publicaciones.

Ambos ejemplos pueden visualizarse a través de los anuncios de 'Hanse', (incluidos en la presentación que acompaña este trabajo), en la que una mujer pilota tranquilamente un velero acompañada por dos hombres. El mensaje sobre impreso indica: "La velocidad sigue a la elegancia"; y en el de Beneteau: "... Beneteau y Marina Estrella juntos; el mejor servicio al navegante".

Como indica Ángela Mcrobbie en More!: Nuevas sexualidades en las revistas para chicas y mujeres. "lo que debemos preguntarnos, es con qué sentido se construyen las imágenes de las mujeres en las revistas, y la respuesta, es que los significados suelen realizar conexiones que siguen colocando a las mujeres en una relación de subordinación, pasividad y subordinación sexual. Así, tanto si se trata de piernas, los pechos, los ojos, los significados que se extraen de esas partes del cuerpo son que estas mujeres están buscando o han logrado ya la aprobación de la mirada masculina." (MCROBBIE, Ángela. (1998) (1996).

Es falso que la mujer no genere por sí misma una actualidad suficiente como para asumir un mayor protagonismo en las revistas náuticas, pero su papel es visto desde una mirada masculina, que la relega siempre a un segundo lugar. Esa mirada impera en la sociedad receptora de estas publicaciones, tanto en hombres como en mujeres, de tal forma que llega a concebirse como un hecho natural y aceptado de antemano sin mayor discusión. El papel de la mujer está preconcebido de antemano.

\section{Publicidad en Pesca y Motor: La utilización de la mujer como fetiche erótico es prioritaria en las revistas de motor y pesca.}

Si se realiza una comparación estadística, se podría establecer la siguiente secuencia: en las revistas analizadas, de cada 100 anuncios y publirreportajes relacionados con la vela, la mujer estaría representada en apenas 5 , y en tan solo 1 podría presentar algún componente erótico, que asimismo siempre está asociado al lujo de la embarcación.

De la misma forma, de cada 100 anuncios y publirreportajes relacionados con la pesca, 95 incluirían la presencia femenina y 93 utilizarían la imagen de la mujer como fetiche erótico y reclamo sexual. Indudablemente, como explica Angela Mcrobbie en More!: Nuevas sexualidades en las revistas para chicas y mujeres, el tema de la publicidad está muy relacionado con la línea editorial de las revistas, y el sistema económico que garantiza su supervivencia: los anunciantes. (MCROBBIE, Angela. (1998) (1996). Esta presencia de la mujer 
como fetiche erótico en las revistas de motor no se da por casualidad, es producto de estudios de mercado que analizan con detalle la identificación del producto y su colocación en el mercado.

Aquí, más que en otras temáticas, se encuentran representadas las teorías de Freud recogidas en el artículo de Laura Mulvey Placer Visual y cine narrativo: "Escoptofilia surge del placer de usar otra persona como objeto de estimulación sexual a través de de la vista. El narcisismo y de la constitución del ego surge con la identificación de la imagen vista"... "En tanto el espectador se identifica con el principal protagonista masculino, proyecta su mirada en la de su semejante subrogado en la pantalla, de tal manera, que el poder del protagonista masculino, en tanto controlador de los acontecimientos, coincida con el poder activo de la mirada erótica, proporcionando a ambos una satisfactoria sensación de omnipotencia". (MULVEY, Laura. 1975).

La venta del barco se estimula con la producción de fantasías y asociaciones sexuales en las que la mujer vuelve a quedar referenciada como objeto pasivo. La utilización de la mujer como fetiche erótico es una constante en todos los anuncios y publirreportajes de motor y pesca editados en Pesca a Bordo y en Skipper, y se repite también en la misma proporción en otras revistas del mercado náutico.Escoptofilia y narcisismo se utilizan como herramientas imprescindibles en los anuncios de la venta de barcos. La imagen femenina es un objeto de recreo, que se ajusta casi siempre a unos cánones establecidos.

En este sentido, Rebeca Maseda en "Madame Sexo: consideraciones acerca de la pornografía femenina" recoge un comentario muy interesante, que se ajusta perfectamente a la concepción de su imagen en la publicidad náutica: "la mujer ha sido considerada objeto, y nadie se ha planteado su posición activa" (MASEDA, Rebeca. 2000).

Por otra parte, la mujer pierde no solo su identidad como individuo, sino su capacidad y su libertad como mujer, al asumir, bajo esa mirada escrutadora del hombre, una identidad pre fabricada. Como indica Rosa $\mathrm{M}^{\mathrm{a}}$ Rodríguez Magda en La feminización de la cultura, "Otra desposesión de la corporalidad la constituye la estética. La mujer es cuerpo y ha de ser "cuerpo bello" según un estereotipo ideal. Esta es una trampa más sutil, pues se disfraza de feminización social. Como si el hecho de que los cánones de belleza encuentren en una mujer su objeto, representara una cierta hegemonía femenina en el imaginario colectivo, cuando lo bien cierto es que constituye un imperativo categórico que fuerza a mujeres concretas a esfuerzos y frustraciones sin fin ante ese ideal nunca alcanzado en el que se cifra su realización como sexo." (RODRÍGUEZ MAGDA, Rosa Mª. 2002).

África Vidal Claramonte en "Diosas, tots Models y mutantes", habla del nacimiento de una nueva religión en el que el culto al cuerpo de la mujer, la nueva divinidad, la mujer perfecta, y estilizada, define el modelo cultural de la mujer que estos anuncios perpetúan y recrean. Son diosas que ponen de 
manifiesto un modelo femenino de consumo, que marcan una nueva era. La mujer divinizada, pero objeto, asociada al producto, a un nivel social, y a un sistema de consumo.

\section{Cuanto mayor es el tamaño del barco y su lujo, más se multiplica la presencia de las mujeres y el reclamo sexual del anuncio.}

Una de las observaciones realizadas en el análisis de las tres publicaciones náuticas muestra cómo el tratamiento del reclamo sexual del anuncio va íntimamente relacionado con el lujo y el tamaño del barco. Esta diferencia está presente en el tratamiento, en la sutilidad, e incluso, en la fórmula de captación del posible comprador.

Producto español: la mujer como fetiche erótico en el sector del motor.

Una de las publicidades insertadas por los anunciantes en las revistas de náutica, y recogida de las revistas de motor, llama la atención por el mensaje y la escenografía utilizados. El objetivo, por supuesto, es vender el barco. El mensaje: "producto Español", impreso sobre una fotografía de un barco de motor de mediana eslora (en torno a los 7 metros), se oferta con el precio de venta, dirigido, por consiguiente, a un público de poder adquisitivo medio. En la proa del barco aparece una mujer con bikini cómodamente tumbada y sugerente. En la popa, un hombre relajadamente sentado (y vestido), charla con otro situado fuera de la embarcación. En una esquina, junto al caso del barco, una fotografía en pequeño muestra el interior de la embarcación: un camarote en el que la mujer que posa arriba está tumbada sobre la cama del barco.

Las connotaciones son inmediatas: el barco y el sexo van unidos en una interpretación que utiliza a la mujer como objeto que refuerza el atractivo del barco. Esta composición resulta incluso un poco burda en comparación con otras publicidades, en las que se provocan sensaciones similares, en cuanto al deseo y la sexualidad, la mujer como objeto receptivo y pasivo y claro fetiche sexual. Este sería el caso de Windy cuando muestra la imagen de una lancha descubierta que recorre el mar, pilotada por un hombre. En la popa, tumbada y con un bañador que hace juego con la decoración del barco, una mujer rubia posa de medio lado. El mensaje impreso: "Windy- su disfrute definitivo, estilo y libertad". En este caso, la embarcación es mucho más grande, y por supuesto, mucho más cara, pero no se vende por su precio sino por las sensaciones que va a producir en su comprador. No necesita 'remarcar' la idea sexual de la utilización del camarote interior para la posesión sexual de la mujer, porque ya va impresa en el diseño y en los modelos utilizados.

Como recoge Hilaria Loyo en Las estrellas y los deseos femeninos bajo la mirada de la historia: el caso de Marlene Dietrich, cuando hace referencia a "Los nuevos tabúes se centran en la independencia, la libertad económica y el auto respeto. Paradójicamente, como señala Tañer, este nuevo culto de dependencia femenina fomentaba la movilidad de clase, "cazar a un hombre con dinero" que los primeros discursos de los primeros años de la depresión 
habían condenado, pues ahora todo lo que necesitamos las mujeres estadounidenses para cumplir su deber cívico como buenas consumidoras, es un hombre con dinero." (LOYO, Hilaria. 2002). Las mujeres presentes en la publicidad náutica de motor y vela representan algo más que la venta de un producto concreto; representan un estatus, un modo de vida, un nivel social, y una forma de contemplar la sociedad en la que viven.

Las imágenes de los anuncios lo muestran claramente, un barco pequeño de clase media, expresa múltiples connotaciones sexuales, unidas a un precio. El barco grande, de clase social elevada, no indica el precio, pero apunta una multiplicación de la satisfacción sexual en el observador masculino. Se multiplica el número de mujeres que posa en el barco, sus posturas y su demanda como objeto pasivo, que solo puede satisfacer al hombre con dinero y poder capaz de manejarlo. La presencia de la mujer dentro de la publicidad como fetiche erótico crece con el tamaño del barco que se vende, o la idea de lujo asociada al producto.

Los barcos de competición pequeños de vela pueden llevar a la mujer asociada como un elemento más de la tripulación o, como mucho, venden el sentido familiar de un barco que va a ser bueno para el comprador y para su familia (la mujer se sienta cómodamente al lado del hombre).

En la medida que crece el precio de la embarcación, su tamaño y sus complementos de gama y lujo, ya sea en vela o en motor, se multiplica la utilización de la imagen de la mujer como reclamo erótico. Crece el número de mujeres en bañador, o muy poco vestidas, que 'embellecen' el barco e incrementan la asociación del placer visual al posible comprador, y refuerzan su ego masculino: Si tienes dinero y poder, podrás tener placer sexual sin límites.

Cuando el lujo se añade como un signo de distinción, la mujer como objeto es imprescindible. No basta competir, hay que dominar; la cultura fálica masculina domina y posee, y para demostrarlo se introduce la figura de la mujer como una diosa perfecta, que complementa y recibe la dominación con una sonrisa, y devuelve el placer visual al hombre.

\section{Comparativa con otras revistas del mercado náutico ¿Las mujeres abusan de los recursos masculinos para potenciar su posición en un mercado de hombres?}

El análisis comparativo de esas tres publicaciones con otras en las que la dirección y control de la revista está protagonizado por mujeres, vuelve a confirmar las ideas expresadas anteriormente, si bien, introduce cambios, cuanto menos, curiosos: Las revistas de motor vuelven a utilizar el cuerpo y la imagen de la mujer como fetiche erótico. Pero curiosamente, las revistas de vela dirigidas por mujeres abusan más del fetiche erótico de la mujer en la publicidad y los publirreportajes de los barcos de vela, que en las publicaciones dirigidas por hombres. 
Contrariamente a lo que podría pre-suponerse, esta dirección femenina tampoco defiende o ensalza el protagonismo de la mujer como sujeto activo en las informaciones y publirreportajes, sino que potencia a la mujer como sujeto pasivo de la mirada del hombre, y la convierte en el primer reclamo para venderle el producto náutico que se le anuncia.

Tal como explica Angela Mcrobbie en More!: Nuevas sexualidades en las revistas para chicas y mujeres, la línea editorial de las revistas, está condicionada por el mercado, y sobre todo por la venta y el anunciante, que son los que sustentan económicamente cada proyecto. Angela Mcrobbie explica también, hasta qué punto la empresa que sustenta cada publicación trata de imprimir una diferencia que identifique el producto frente a otras publicaciones, con el fin de encontrar un público afín y por tanto, una aceptación comercial que justifique su publicación.

Sin embargo, en relación con lo que se ha comentado cabe hacer una diferencia sustancial, la publicidad viene impresa por el anunciante, es la misma en todas las revistas náuticas; mientras que el publirreportaje conlleva una línea editorial propia en combinación con los deseos del anunciante. Estas revistas, de dirección femenina, incluyen más publirreportajes con figuras femeninas como reclamo sexual que las revistas de la editorial Curt Ediciones, dirigida por hombres.

Asimismo, en las revista náuticas dirigidas por mujeres, aunque la línea editorial viene marcada por la línea empresarial, el posicionamiento de las redactoras o directoras frente a los temas que presentan, muestra un predominio en la utilización de los reclamos masculinos y la imagen de la mujer como fetiche erótico; estos elementos pueden a llegar a multiplicarse por encima de otras publicaciones similares presentadas por hombres.

Las editoriales y los postulados asumidos por estas mujeres, recuerdan a la teoría esbozada por Eva Parrondo en Feminidad y mascarada: "Por otro lado también existen fantasías (sueños diurnos), tipos de placer o identificaciones en relación con los propios textos que tienen un carácter específico en función del contexto histórico, social o cultural de las espectadoras". Identificación hazañas. ".(PARRONDO, Eva. 1996)

Son mujeres que viven en un mundo de hombres y compiten con productos realizados por hombres. Defienden abiertamente la igualdad de la mujer en los deportes náuticos, reclaman su aceptación, pero en sus publicaciones, sus editoriales y cuanto el producto está directamente relacionado con su dirección, la mujer queda relegada, como si en su rebeldía por la diferenciación sexual se identificaran con los modelos masculinos de héroes, lo que acaba provocando una contradicción en cuanto al pensamiento y su exposición.

\section{¿Discriminación positiva?}

La utilización de los recursos masculinos por parte de las mujeres, para 
sobresalir y sobrevivir en un sector tan masculinizado como la náutica, no es casual. Un ejemplo que puede ilustrar esta utilización ha quedado reflejado en una campaña de comunicación presentada durante la temporada de regatas de alto nivel del 2004.

El tema al que hace alusión este ejemplo, se centra en la presentación de tres barcos tripulados única y exclusivamente por mujeres en el Campeonato de España de Cruceros, un sector dominado casi exclusivamente por hombres. La empresa de comunicación que llevó a cabo la campaña de dos de estos barcos, partió de un elemento identificador: la diferencia sexual de las navegantes con relación al resto de los equipos.

El objetivo estaba claro, estos barcos no tenían posibilidad de ganar regatas, pero necesitaban una repercusión mediática que garantizara a sus patrocinadores la aparición en los medios de comunicación. La campaña, dirigida por una mujer, se basó en la discriminación positiva, el abuso de los modelos masculinos, y la diferencia sexual de las protagonistas, para crear un referente activo, y no pasivo.

Los términos utilizados en las notas de prensa llegaron a ser agresivos: "guerra de mujeres"............" Las mujeres se enfrentan......" "Amigas en tierra, competidoras en el mar". Las herramientas utilizadas no pretendían degradar a las mujeres participantes, sino utilizar su diferenciación sexual para potenciar su capacidad de convertirse en sujetos activos y generadores de los mismos modelos que identificaban a sus contrincantes masculinos.

En suma, se planteó como una forma de dar la vuelta a la teoría del espejo de Rosa $\mathrm{M}^{a}$ Rodríguez Magda, reforzando su tesis de que las mujeres deben producir su propia cultura y generar una mirada propia sobre ellas mismas. Una fórmula para reescribir el guion ya enunciado por la sociedad masculina para, tal como promueve Teresa de Lauretis, "utilizar el conocimiento y sus estrategias narrativas para modificar el posicionamiento de las mujeres".

Como se había calculado en un principio, el hecho de que las tripulaciones fueran femeninas, llamó la atención de los medios de comunicación, cosechó la simpatía y obtuvo el respaldo mediático de los medios y los profesionales de la información, tanto de los hombres como de las mujeres periodistas. Los barcos no ganaron regatas, pero obtuvieron una importante repercusión en prensa, radio y televisión. Los patrocinadores quedaron contentos y la participación femenina fue aceptada con respeto.

\section{Bibliografía}

GÁMEZ FUENTES, Ma José (2001) "El cuerpo materno en la cultura occidental: una aproximación a diferentes enfoques teóricos", dossier Feministes, $\mathrm{n}^{\circ}$ 5, (número monográfico La construcció del cos, una crítica des del gènere, ed. Sonia Reverter Bañón, pp.113-122.

GÁMEZ FUENTES, Mª José (2003) “Introducción a los estudios de género 
aplicados a los medios de comunicación", Asparkía Investigació Feminista, $\mathrm{n}^{\circ} 14$ (En prensa).

GÁMEZ FUENTES, Ma José (2004) "Antecedentes psicoanalíticos: la figura materna en el desarrollo del Sujeto". En Cinematergrafía. "La madre en el cine y la literatura de la democracia española”, Castellón: Ellago y Universitat Jaume I (en prensa).

GERAGHTY, Christine (1998) (1996), "Feminismo y consumo mediático", en Estudios culturales y comunicación, ed. James Curran et al., Barcelona: Piados, 455-479.

KUHN, Annette (2002) "Géneros de mujeres. Teoría sobre el melodrama y el culebrón”, secuencias, n.15, 7-17.

LOYO, Hilaria (2002) "Las estrellas y los deseos femeninos bajo la mirada de la historia: El caso de Marlene Dietrich". Secuencias, n.15, 18-31.

MASEDA, Rebeca (2000), "Madame Sexo: Consideraciones acerca de la pornografía femenina", Secuencias, n.12, 23-36.

MCROBBIE, Ángela (1998) (1996) “More!: nuevas sexualidades en las revistas para chicas y mujeres". Estudios Culturales y comunicación, ed. James Curran et al., Barcelona: Piados, 263-296).

MULVEY, Laura (1975) "Placer Visual y cine narrativo". Centro de Semiótica y teoría del espectáculo. Universidad de Valencia \& Asociación Vasca de semiótica. Ed. Joseph-Vicent Gavaldà, Luis Puig, Manuel Talens.

PARRONDO, Eva (1996) "Feminidad y mascarada en lo que el viento se llevó y Jezabel". Valencia: Episteme.

RODRÍGUEZ MAGDA, Rosa Mª (2002) “¿Feminizació de la cultura?”, Debats, 76, 8- 17.

SENENT, Miguel (1993) "Memorias del Grao de Castellón". Servicio de Publicaciones Diputación de Castellón.

VIDAL CLARAMONTE, África (2002) "Diosas, tots models y muntantes", Debats, n 76, 126-137.

Revistas náuticas

100 X100 REGATAS (2004) Curt Ediciones. Barcelona

BARCOS A MOTOR (2004-2006) Grupo V.

Barcelona BARCOS A VELA (2004-2006) Grupo V. Barcelona

GRANDES ESLORAS (2004) MC Ediciones. Barcelona 
NAVEGAR (2004) Motor Press Ibérica. Barcelona

NÁUTIC PRESS (2004) Editorial Men-Car. Barcelona

PESCA A BORDO (2004) Curt Ediciones. Barcelona

PESCA DE ALTURA (2004) MC Ediciones. Barcelona

SOLO PESCA (2004) MC Ediciones. Barcelona

SKIPPER (2004) Curt Ediciones. Barcelona

YATE (2004) MC Ediciones. Barcelona 
Esperanza Molina 